\title{
Effect of transplanted adipose-derived stem cells in mice exhibiting idiopathic pulmonary fibrosis
}

\author{
HONGBIN JIANG ${ }^{1,2}$, JUN ZHANG $^{3}$, ZHEMIN ZHANG $^{4}$, SHENGXIANG REN $^{5}$ and CHUANSEN ZHANG ${ }^{1}$ \\ ${ }^{1}$ Department of Anatomy, Second Military Medical University; Departments of ${ }^{2}$ Endoscopy, \\ ${ }^{3}$ Laboratory Medicine, ${ }^{4}$ Respiratory and ${ }^{5}$ Oncology, Shanghai Pulmonary Hospital, \\ Tongji University School of Medicine, Shanghai 200433, P.R. China
}

Received September 3, 2014; Accepted May 15, 2015

DOI: $10.3892 / \mathrm{mmr} .2015 .4178$

\begin{abstract}
Stem cell-based cell therapy has provided a promising method for the treatment of pulmonary diseases, including idiopathic pulmonary fibrosis (IPF). Furthermore, adipose-derived stem cells (ADSCs) have been reported to be effective in lung repair and regeneration. In the current study, IPF was induced in mice by intratracheal instillation of bleomycin (BLM), and ADSCs were delivered systemically into the mice via the tail vein to evaluate the effects of ADSC transplantation. The ADSC engraftment rate and morphometric changes in lung tissue samples in vivo were investigated by histochemistry and immunohistochemistry, as well as by western blotting. The results indicated that ADSCs may relieve IPF and provide a significant contribution to lung repair when administered at an early stage.
\end{abstract}

\section{Introduction}

Idiopathic pulmonary fibrosis (IPF) is a refractory and lethal form of progressive fibrotic lung disorder that is characterized by fibroblast proliferation, extracellular matrix deposition and progressive lung scarring. IPF exhibits the histopathologic pattern of usual interstitial pneumonia and the incidence of IPF worldwide has gradually increased annually (1). Mesenchymal stem cell (MSC) therapy has previously been reported as a promising method for lung tissue regeneration and protection (2). Zhang et al revealed that MSCs are important in lung repair and promote collagen fiber deposition following induction of secondary damage in alveolar type (AT) II cells using rAAV-SPA-TK, which involves hypoxia-inducible factor- $1 \alpha$ and stromal cell-derived factor 1 signaling (3). Moodley et al reported that human umbilical cord MSCs

Correspondence to: Professor Chuansen Zhang, Department of Anatomy, Second Military Medical University, 800 Xiangyin Road, Shanghai 200433, P.R. China

E-mail: zhangchuansen222@163.com

Key words: idiopathic pulmonary fibrosis, adipose-derived stem cells, bleomycin, transplantation reduce fibrosis of bleomycin (BLM)-induced lung injury (4), and Gupta et al reported that intrapulmonary delivery of bone marrow-derived MSCs (BMSCs) improves survival and attenuates endotoxin-induced acute lung injury in mice (5).

However, reports on the effect of transplanted adipose-derived stem cells (ADSCs) in mice with IPF were rare. When compared with BMSCs, ADSCs are more abundant, widely available and possess similar properties to BMSCs, such as multiple differentiation potential, high proliferation and immunoregulatory ability $(6,7)$. Therefore, investigating the effect of ADSCs in mice with IPF was required.

In the present study, it was hypothesized that transplanted ADSCs could promote the repair of lung injury and relieve IPF. To test the hypothesis, ADSCs were delivered systemically into IPF mice via the tail vein to assess the effects.

\section{Materials and methods}

Animals. Sixty C57BL/6 mice (weight, 12-16 g) were procured from the Center of Experimental Animals, Shanghai Medical College, Fudan University (Shanghai, China). Mice were given free access to water and a standard rodent diet (no. 2920; Harlan Laboratories, Indianapolis, IN, USA).

To induce fibrotic changes, the animals were intratracheally injected with BLM (Blenoxane; Mead Johnson, Princeton, NJ, USA) at a dose of $2.5 \mathrm{U} / \mathrm{kg}$ mouse body weight, as previously described (8). All of the animal studies were reviewed and approved by the Ethics Committee of Tongji University School of Medicine (Shanghai, China).

Isolation and expansion of mouse ADSCs. ADSCs were harvested from the inguinal groove of the mice. The adipose tissue samples were isolated and incubated in alpha-minimal essential medium (MEM) containing $10 \%$ fetal bovine serum (FBS; GE Healthcare Life Sciences, Logan, UT, USA) and $0.1 \%$ collagenase type IV solution at $37^{\circ} \mathrm{C}$ for $45-60 \mathrm{~min}$. The digested tissues were filtered through $45-\mathrm{mm}$ nylon filter mesh (BD Biosciences, Franklin Lakes, NJ, USA) and centrifuged at $157 \mathrm{x} g$ for $5 \mathrm{~min}$. Following removal of the supernatant, pellets was resuspended in alpha-MEM supplemented with $10 \% \mathrm{FBS}$, and the cells were plated in $10-\mathrm{cm}$ tissue culture dishes and cultured at $37^{\circ} \mathrm{C}$ in a $5 \% \mathrm{CO}_{2}$ incubator. The culture medium 
was changed every two days, and the cells were passaged after reaching 80-90\% confluence (9).

Experimental design. The mice were randomly divided into four groups: i) A, normal control; ii) B, IPF; iii) C, $\mathrm{IPF}+$ phosphate-buffered saline (PBS); and iv) D, IPF + ADSC transplantation. ADSCs $\left(1 \times 10^{6}\right.$ cells $\left./ \mathrm{ml}\right)$ were systemically administered to the mice in $\sim 250 \mu \mathrm{l}$ PBS via the tail vein, as described previously (3). The control group received the same volume of PBS only. The mice were sacrificed on day 7, and the lung tissues were sampled for morphometric analysis and immunohistochemical staining.

TUNEL assay for apoptosis detection. Paraffin-embedded samples (thickness, $4 \mu \mathrm{m}$ ) was rehydrated and then incubated with Proteinase K solution (Life Technologies, Carlsbad, CA, USA) for $30 \mathrm{~min}$ at room temperature. The samples were incubated with TUNEL reaction solution (BD Pharmingen, San Diego, CA, USA) at $37^{\circ} \mathrm{C}$ for $60 \mathrm{~min}$ after two washes with PBS. As previously described (10), the transforming solution was added and the samples were incubated at $37^{\circ} \mathrm{C}$ for 30 min. Staining was developed with 3,3'-diaminobenzidine tetrahydrochloride for $15 \mathrm{~min}$. The samples were subsequently counterstained with hematoxylin for $15 \mathrm{~min}$, dehydrated in graded alcohol and covered with resin. Positive staining was indicated by a nuclei that was pale brown.

Morphometric analysis and immunohistochemical staining. Cryosections (thickness, $5 \mu \mathrm{m}$ ) were stained with hematoxylin and eosin for morphometry or collagen fiber detection. Additional cryosections were used for the immunostaining of the matrix metalloproteinase (MMP)-2 antibody (cat. no. ab124292; Abcam, Cambridge, UK) and the MMP-9 antibody (cat. no. ab38898; Abcam) as previously described (11).

Hydroxyproline (Hyp) detection. The Hyp level in the lungs of mice was used to quantify the lung collagen content, as described previously (10). At the time of sacrifice, the mouse lungs were removed and any extra pulmonary airways and blood vessels were excised and discarded. The lung parenchyma was homogenized in $1.0 \mathrm{ml} \mathrm{PBS}$ and $1.0 \mathrm{ml} 12 \mathrm{~N} \mathrm{HCl}$ was added. The samples were subsequently hydrolyzed at $110^{\circ} \mathrm{C}$ for $24 \mathrm{~h}$ and $5 \mu \mathrm{l}$ of each sample was mixed with $5 \mu \mathrm{l}$ citrate/acetate buffer (5\% citric acid, $1.2 \%$ glacial acetic acid, $7.25 \%$ sodium acetate and $3.4 \%$ sodium hydroxide). Chloramine-T solution $(100 \mu \mathrm{l} ; 1.4 \%$ chloramine-T, $10 \% \mathrm{~N}$-propanol and $80 \%$ citrate/acetate buffer) was added and the mixture was incubated for $20 \mathrm{~min}$ at room temperature. Ehrlich's solution $(1 \mathrm{ml})$ was added and the samples were incubated at $65^{\circ} \mathrm{C}$ for $18 \mathrm{~min}$. The absorbance was measured at $550 \mathrm{~nm}$ on a spectrophotometer (Lambda 20 UV VIS; Perkin Elmer, Norwalk, CT, USA).

Measurement of bronchoalveolar lavage fluid (BALF). An enzyme-linked immunosorbent assay kit (Abcam) was used to detect the levels of BALF cytokines [interleukin-1 (IL-1), platelet-derived growth factor (PDGF), and tumor necrosis factor (TNF)- $\alpha$ ] in accordance with the manufacturer's instructions.

Western blotting. Tissues were harvested on ice in a radioimmunoprecipitation assay buffer $(50 \mathrm{mmol} / \mathrm{l}$ Tris- $\mathrm{HCl}, \mathrm{pH} 7.4,0.25 \%$
Na-deoxycholate, $1 \mathrm{mmol} / 1$ EDTA, $1 \mathrm{mmol} / 1$ phenylmethylsulfonyl fluoride, $150 \mathrm{mmol} / 1 \mathrm{NaCl}, 1 \mathrm{mg} / \mathrm{ml}$ aprotinin, $1 \mathrm{mg} / \mathrm{ml}$ pepstatin, $1 \mathrm{mg} / \mathrm{ml}$ leupeptin and $1 \mathrm{mmol} / 1$ sodium fluoride) and centrifuged at $12,000 \mathrm{x} \mathrm{g}$ for $18 \mathrm{~min}$ at $4^{\circ} \mathrm{C}$. Protein concentrations were determined using a bicinchoninic acid protein assay (Abcam) with bovine serum albumin (Sigma-Aldrich, St. Louis, MO, USA) as the standard. The samples were boiled in sample buffer at $100^{\circ} \mathrm{C}$ for $15 \mathrm{~min}$. Equal quantities of protein (110 $\mu \mathrm{g}$ per sample) were separated by electrophoresis on 7.6-11\% Tris-glycine sodium dodecyl sulfate polyacrylamide gels. Following electrophoresis, the proteins were transferred onto nitrocellulose membranes that were blocked and incubated with anti-MMP-2 (1:300; Abcam) and anti-MMP-9 (1:500; Abcam) at $4{ }^{\circ} \mathrm{C}$ overnight. After washing, the membranes were incubated with anti-rabbit secondary antibodies (1:2000; Life Technologies) and reacted with enhanced chemiluminescence horseradish peroxidase detection reagents (GE Healthcare Life Sciences). The western blots were scanned and analyzed on a Storm 860 Phosphorimager (GE Healthcare).

Statistical analysis. Values are expressed as means \pm standard deviation and were analyzed by one-way analysis of variance. $\mathrm{P}<0.05$ was considered to indicate a statistically significant difference.

\section{Results}

ADSC intervention alleviated IPF. Mice in the IPF and $\mathrm{IPF}+\mathrm{PBS}$ treatment groups demonstrated severe alveolar destruction compared with that of the normal control group and the ADSC intervention group. Pathological changes were observed, such as a significant increase in collagen fibers around the bronchi and vessels of the IPF and IPF + PBS treatment groups, and light blue collagen fibers were identified in the interstitial lung. These data indicate that ADSC intervention alleviates IPF (Fig. 1).

ADSC transplantation decreases the apoptosis of alveolar epithelial cells. As shown in Fig. 2, the cell nuclei of the apoptotic alveolar epithelial cells were stained yellow. The number of apoptotic cells in the ADSC transplantation group was less than that of groups $\mathrm{B}$ and $\mathrm{C}$, indicating that the transplantation of ADSCs contributes to a decrease in apoptotic lung cells.

Immunohistochemical staining of MMP-2 and MMP-9. A large number of cells with a yellow-stained cytoplasm were identified in the IPF and the IPF + PBS treatment groups, although not in the normal control group, indicating increased collagen deposition in these two groups. However, no significant difference was observed between the IPF and the IPF + PBS treatment groups (P>0.05; Figs. 3 and 4).

Hyp content in lung tissue samples. When compared with that of groups A and D, an increase in the Hyp content was observed in groups $\mathrm{B}$ and $\mathrm{C}$, indicating that collagen deposition increased following lung IPF, and ADSC transplantation decreased the occurrence of lung fibrosis $(\mathrm{P}<0.05$; Fig. 5).

Increased IL-1, PDGF and TNF- $\alpha$ levels in the BALF of each $I P F$ group. The concentrations of IL-1, PDGF, and TNF- $\alpha$ in the 


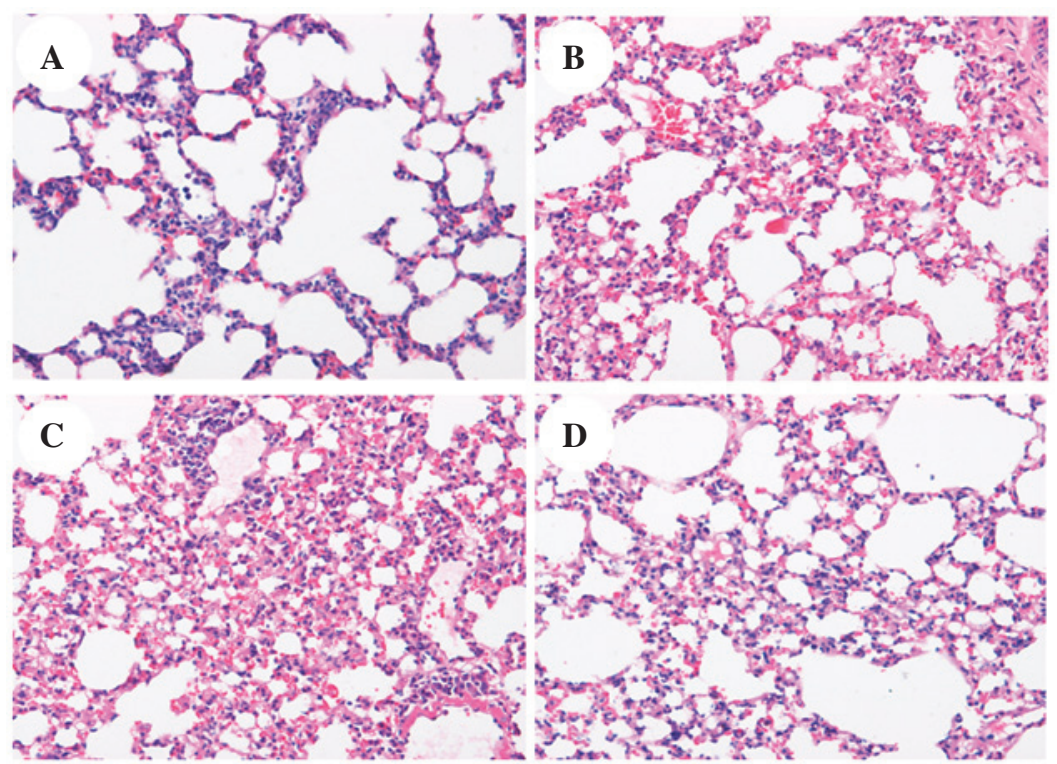

Figure 1. H\&E staining of lung tissue samples. (A) Normal control group. (B) IPF group. (C) IPF + phosphate-buffered saline treatment group. (D) IPF + adipose-derived stem cell treatment group. In groups B and C, H\&E staining of the lung sections revealed significant collagen deposition, an increased linear intercept, an increased pulmonary alveolar area, as well as a decreased alveolar number. However, a significant decrease of lung fibrosis was noted in group D (magnification, x40). H\&E, hematoxylin and eosin; IPF, idiopathic pulmonary fibrosis.
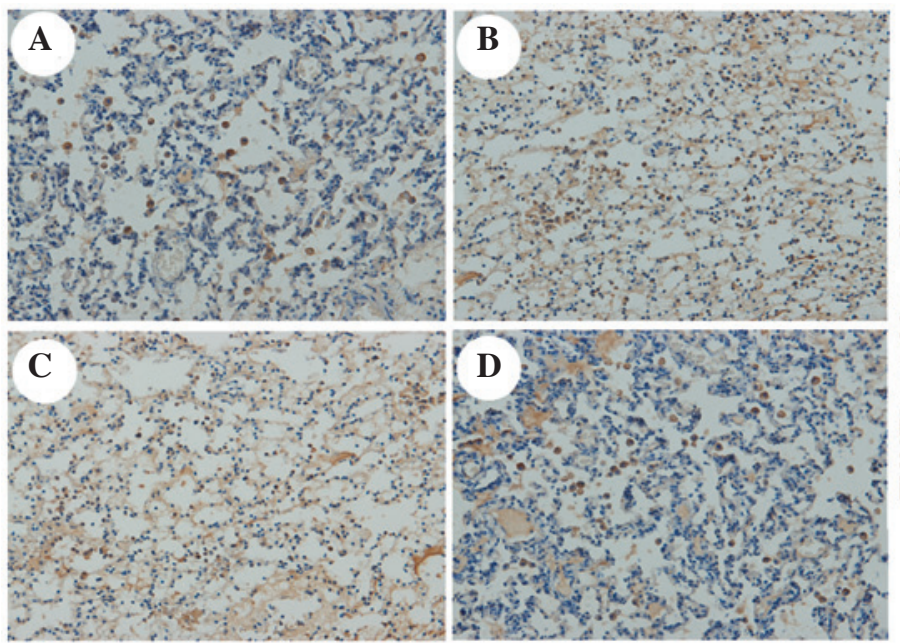

$\mathbf{E}$

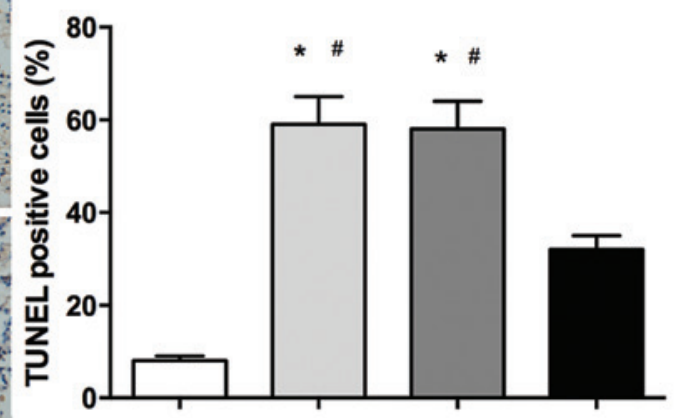

Figure 2. Apoptosis of alveolar epithelial cells using a TUNEL assay. (A-D) The number of apoptotic cells was identified to be significantly increased in groups B (IPF) and C (IPF + phosphate-buffered saline) compared with those of groups A (normal control) and D (IPF + ADSCs). A significant difference was noted in the number of TUNEL-positive cells between groups B and D (magnification, $\mathrm{x} 40$ ). (E) ADSC transplantation decreased the apoptosis of alveolar epithelial cells. ("P<0.05, compared with Group A; ${ }^{\#} \mathrm{P}<0.05$, compared with Group D). IPF, idiopathic pulmonary fibrosis; ADSCs, adipose-derived stem cells.

BALF of groups B, C and D were observed to be significantly increased when compared with those observed in the control group (A). The expression of IL-1, PDGF,and TNF- $\alpha$ was not significantly different between groups $\mathrm{B}$ and $\mathrm{C}$; however, the cytokine level was significantly decreased in the ADSC transplantation group, when compared with that of groups B and C. These results indicate that transplantation of ADSCs decreases the production of these particular proinflammatory factors within the mouse lung (Fig. 6).

\section{Discussion}

It has been reported that MSCs may be used for the treatment of lung disease, such as chronic obstructive pulmonary disease (COPD) and IPF (12-15). Furthermore, BMSCs have been identified as effective in the therapy of pulmonary fibrosis (16-18). As the harvesting of BMSCs is considered to be difficult and low yielding, ADSCs may potentially be an ideal cell source, owing to the biological features that are comparable with BMSCs. Therefore, in the current study, the effect of transplanted ADSCs in mice with IPF was evaluated.

The IPF mouse model was established by injecting mice with BLM (a glycopeptide antibiotic that is produced by the bacterium, Streptomyces verticillus), which causes pulmonary fibrosis and impairs lung function. The epithelium of the mouse airway was subjected to BLM exposure, which resulted in the development IPF and cystic fibrosis (19). 

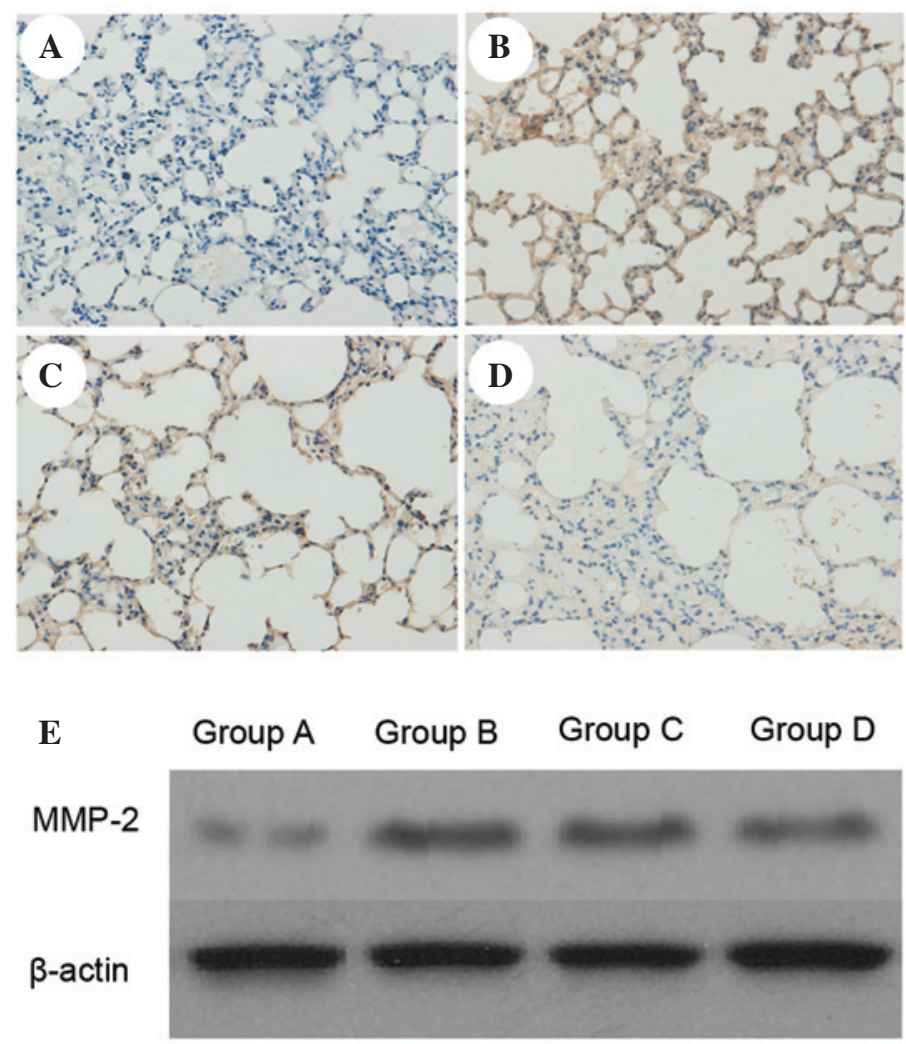

Figure 3. MMP-2 expression in lung tissue. (A-D) Numerous cells with a yellow-stained cytoplasm were observed in the IPF (B) and IPF + PBS (C) groups, but not in the normal control group (A), indicating increased collagen deposition in the IPF and IPF + PBS groups (magnification, $\mathrm{x} 40$ ). (E) Western blotting revealed that there was a decreased expression of MMP-2 in group D (IPF + ADSCs) compared with groups B and C. No significant difference in MMP-2 expression was noted between the IPF and the IPF + PBS groups. MMP, matrix metalloproteinase; IPF, idiopathic pulmonary fibrosis; PBS, phosphate-buffered saline; ADSCs, adipose-derived stem cells.
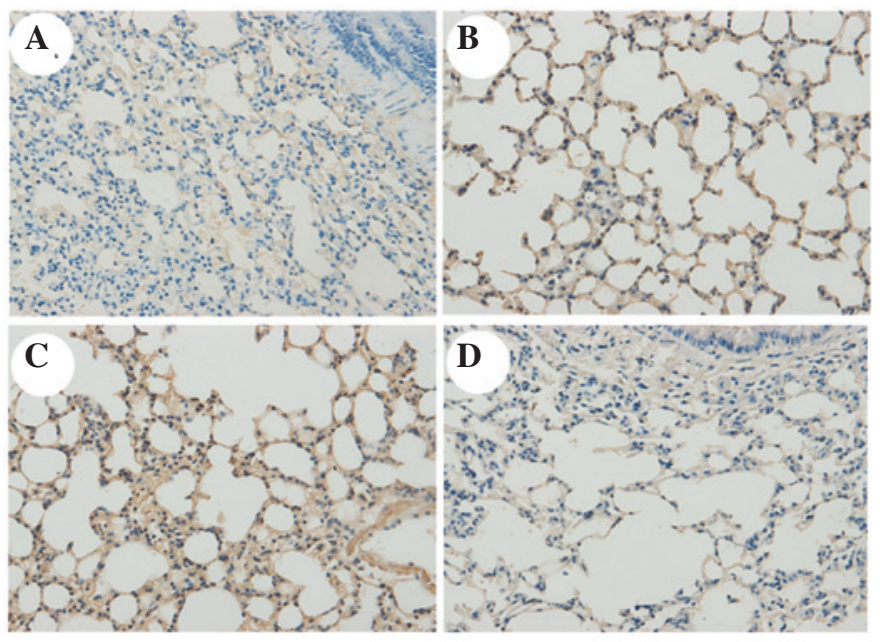

$\mathbf{E}$

Group A Group B Group C Group D

MMP-9

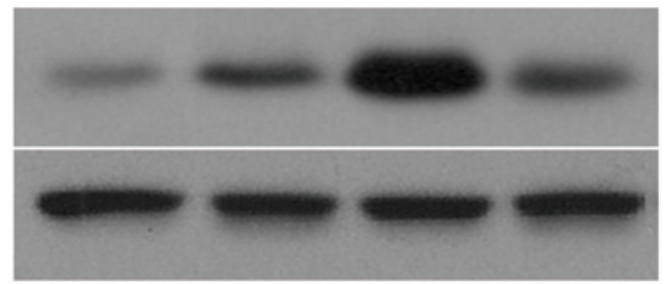

Figure 4. MMP-9 expression in lung tissue. (A-D) Immunohistochemistry (magnification, x40) revealed increased collagen deposition in the IPF (B) and IPF + PBS (C) groups. (E) Western blotting showed a decreased expression of MMP-9 in group D (IPF + ADSCs) compared with groups B and C. However, no significant difference was noted among the IPF and the IPF+PBS groups. MMP-9, matrix metalloproteinase; IPF, idiopathic pulmonary fibrosis; PBS, phosphate-buffered saline; ADSCs, adipose-derived stem cells. 


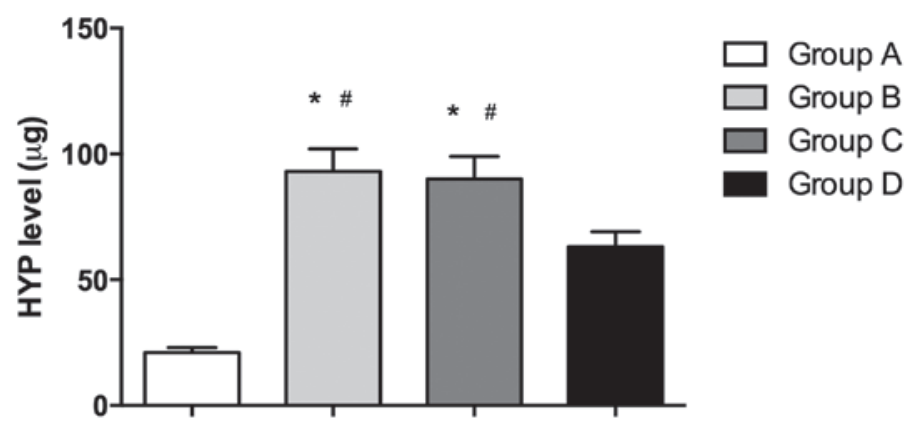

Figure 5. Hyp content in lung tissue samples. A significant increase of Hyp content in group B (IPF) and C (IPF + phosphate buffered saline) was observed compared with that in groups A (normal control) and D (IPF + adipose-derived stem cells). Hyp, hydroxyproline; IPF, idiopathic pulmonary fibrosis ("P $<0.05$, compared with Group A; ${ }^{\#} \mathrm{P}<0.05$, compared with Group D).

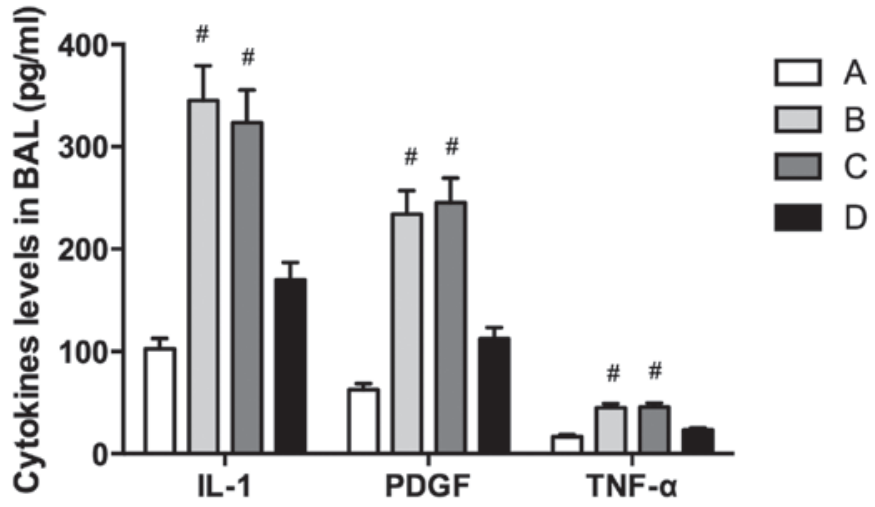

Figure 6. IL-1, PDGF and TNF- $\alpha$ levels in the BALF of each group. When compared with the cytokine level in group D (IPF + ADSCs), the concentrations of IL-1, PDGF and TNF- $\alpha$ in the BALF of groups B (IPF) and C (IPF + phosphate-buffered saline) were significantly increased. The expression of IL-1, PDGF and TNF- $\alpha$ was not significantly different between groups B and C; however, the cytokine level was significantly decreased in the ADSC transplantation group when compared with that in groups B and $\mathrm{C}$. ( $\mathrm{P}<0.05$, compared with Group A; ${ }^{*} \mathrm{P}<0.05$, compared with Group D). BALF, bronchoalveolar lavage fluid; IL-1, interleukin-1; PDGF, platelet-derived growth factor; TNF- $\alpha$, tumor necrosis factor alpha; IPF, idiopathic pulmonary fibrosis; ADSCs, adipose-derived stem cells.

Previous studies have identified that AT II cells may be involved in the repair and regeneration of damaged alveoli in cases of IPF; however, this type of cell is rare $(20,21)$. Therefore, the transplantation of exogenous stem cells to enhance the repair capacity of the lungs may provide an effective alternative. In the current study, the effect of ADSC transplantation into mice with IPF was investigated. Histological staining revealed thickening of the pulmonary interstitium, narrowing alveolar width, and pulmonary fibrosis, which were observed in the IPF and the IPF + PBS groups, whereas attenuating responses were observed in the ADSC transplantation group. The collagen fiber deposition was also apparent in the IPF and the IPF + PBS groups. This finding indicates that injection of ADSCs decreases pulmonary fibrosis; however, the specific underlying mechanism remains unclear. Recent studies have indicated that lung MSCs are triggered to differentiate into myofibroblasts in a local microenvironment, which induces pulmonary fibrosis $(22,23)$. In the present study, the ADSCs were injected into mice $1 \mathrm{~h}$ after pulmonary fibrosis induction, and it was hypothesized that ADSCs could not differentiate into myofibroblasts at this early stage.

MMP is a type of proteinase that is capable of degrading the extracellular matrix, which has been reported as vital in lung fibrosis (24). MMP-2 and MMP-9 levels were considered to be directly proportional to the occurrence of pulmonary fibrosis, and overactivation of MMP-2 may be the cause of type IV collagen degradation, which is involved in the initiation of lung fibrosis. In the present study, immunohistochemical staining of MMP-2 and MMP-9 revealed that the expression of MMPs in the lungs of mice increased following BLM treatment. The same results were also observed during western blot analysis. Kim et al reported that the MMP-2/MMP-9 activity was upregulated in the early stage of lung fibrosis, while the expression of tissue inhibitor of metalloproteinases, TIMP1/2 increased and MMP-2/MMP-9 activity decreased in the later time period (25). In addition, it has been reported that the level of MMPs in the serum and sputum of COPD patients increased, although the specific association between MMPs and COPD requires further investigation. Notably, the expression of MMPs decreased significantly following ADSC transplantation, indicating that ADSC transplantation may be involved in the process of lung repair. It was hypothesized in the current study that ADSCs migrate into the injured lung and proliferate, thus inhibiting fibroblast proliferation and collagen deposition.

Additionally, Hyp has been recognized as a key marker of collagen deposition in pulmonary fibrosis. Therefore, in the present study, the expression of Hyp was detected and the result revealed increased collagen fiber deposition in the IPF and 
IPF + PBS groups. Wang et al also reported that immediate MSC transplantation following fibrosis induction decreased the Hyp content (26), however, the MSC transplantation at a later stage of fibrosis induction in mice demonstrated no significant improvement to lung fibrosis, indicating that stem cells transplantation at an early stage may be critical in lung repair.

In conclusion, ADSC transplantation in the lungs may enhance lung injury repair and extenuate lung fibrosis when administered at an early stage, thus providing an effective option for the treatment of lung diseases, such as IPF and COPD.

\section{Acknowledgements}

The present study was supported by the Shanghai Municipal Natural Science Foundation (no. 14ZR1434500).

\section{References}

1. Tzouvelekis A, Koliakos G, Ntolios P, Baira I, Bouros E, Oikonomou A, Zissimopoulos A, Kolios G, Kakagia D, Paspaliaris V, et al: Stem cell therapy for idiopathic pulmonary fibrosis: a protocol proposal. J Transl Med 9: 182, 2011.

2. D'Agostino B, Sullo N, Siniscalco D, De Angelis A and Rossi F: Mesenchymal stem cell therapy for the treatment of chronic obstructive pulmonary disease. Expert Opin Biol Ther 10: 681-687, 2010 .

3. Zhang WG, He L, Shi XM, Wu SS, Zhang B, Mei L, Xu YJ, Zhang ZX, Zhao JP and Zhang HL: Regulation of transplanted mesenchymal stem cells by the lung progenitor niche in rats with chronic obstructive pulmonary disease. Respir Res 15: 33, 2014.

4. Moodley Y, Atienza D, Manuelpillai U, Samuel CS, Tchongue J, Ilancheran S, Boyd R and Trounson A: Human umbilical cord mesenchymal stem cells reduce fibrosis of bleomycin-induced lung injury. Am J Pathol 175: 303-313, 2009.

5. Gupta N, Su X, Popov B, Lee JW, Serikov V and Matthay MA: Intrapulmonary delivery of bone marrow-derived mesenchymal stem cells improves survival and attenuates endotoxin-induced acute lung injury in mice. J Immunol 179: 1855-1863, 2007.

6. Taghi GM, Ghasem Kashani Maryam H, Taghi L, Leili H and Leyla M: Characterization of in vitro cultured bone marrow and adipose tissue-derived mesenchymal stem cells and their ability to express neurotrophic factors. Cell Biol Int 36: 1239-1249, 2012.

7. Nakao N, Nakayama T, Yahata T, Muguruma Y, Saito S, Miyata Y, Yamamoto K and Naoe T: Adipose tissue-derived mesenchymal stem cells facilitate hematopoiesis in vitro and in vivo: advantages over bone marrow-derived mesenchymal stem cells. Am J Pathol 177: 547-554, 2010.

8. Ding L, Dolgachev V, Wu Z, Liu T, Nakashima T, Wu Z, Ullenbruch M, Lukacs NW, Chen Z and Phan SH: Essential role of stem cell factor-c-Kit signalling pathway in bleomycin-induced pulmonary fibrosis. J Pathol 230: 205-214, 2013.

9. Liu HY, Chiou JF, Wu AT, Tsai CY, Leu JD, Ting LL, Wang MF, Chen HY, Lin CT, Williams DF, et al: The effect of diminished osteogenic signals on reduced osteoporosis recovery in aged mice and the potential therapeutic use of adipose-derived stem cells. Biomaterials 33: 6105-6112, 2012.
10. Hattori N, Degen JL, Sisson TH, Liu H, Moore BB Pandrangi RG, Simon RH and Drew AF: Bleomycin-induced pulmonary fibrosis in fibrinogen-null mice. J Clin Invest 106: 1341-1350, 2000.

11. Monteiro-Amado F, Castro-Silva II, Lima CJ, Soares FA, Kowalski LP and Granjeiro JM: Immunohistochemical evaluation of MMP-2, MMP-9 and CD31/microvascular density in squamous cell carcinomas of the floor of the mouth. Braz Dent J 24: 3-9, 2013.

12. Inamdar AC and Inamdar AA: Mesenchymal stem cell therapy in lung disorders: pathogenesis of lung diseases and mechanism of action of mesenchymal stem cell. Exp Lung Res 39: 315-327, 2013.

13. Moodley Y, Manuelpillai U and Weiss DJ: Cellular therapies for lung disease: a distant horizon. Respirology 16: 223-237, 2011.

14. Sdrimas K and Kourembanas S: MSC microvesicles for the treatment of lung disease: a new paradigm for cell-free therapy. Antioxid Redox Signal 21: 1905-1915, 2014.

15. Huleihel L, Levine M and Rojas M: The potential of cell-based therapy in lung diseases. Expert Opin Biol Ther 13: 1429-1440, 2013.

16. Rhieu BH, Epperly MW, Cao S, Franicola D, Shields D, Goff J, Wang $\mathrm{H}$ and Greenberger JS: Increased hematopoiesis in long-term bone marrow cultures and reduced irradiation-induced pulmonary fibrosis in Von Willebrand factor homologous deletion recombinant mice. In Vivo 28: 449-456, 2014.

17. Gilpin SE, Lung K, de Couto GT, Cypel M, Sato M, Singer LG, Keshavjee S and Waddell TK: Bone marrow-derived progenitor cells in end-stage lung disease patients. BMC Pulm Med 13: 48, 2013.

18. Aguilar S, Scotton CJ, McNulty K, Nye E, Stamp G, Laurent G, Bonnet D and Janes SM: Bone marrow stem cells expressing keratinocyte growth factor via an inducible lentivirus protects against bleomycin-induced pulmonary fibrosis. PLoS One 4: e8013, 2009.

19. Kalayarasan S, Sriram N, Soumyakrishnan S and Sudhandiran G: Diallylsulfide attenuates excessive collagen production and apoptosis in a rat model of bleomycin induced pulmonary fibrosis through the involvement of protease activated receptor- 2 . Toxicol Appl Pharmacol 271: 184-195, 2013.

20. Rawlins EL: Lung epithelial progenitor cells: lessons from development. Proc Am Thorac Soc 5: 675-681, 2008.

21. Reynolds SD and Malkinson AM: Clara cell: progenitor for the bronchiolar epithelium. Int J Biochem Cell Biol 42: 1-4, 2010.

22. Popova AP, Bozyk PD, Goldsmith AM, Linn MJ, Lei J, Bentley JK and Hershenson MB: Autocrine production of TGF-beta1 promotes myofibroblastic differentiation of neonatal lung mesenchymal stem cells. Am J Physiol Lung Cell Mol Physiol 298: L735-L743, 2010.

23. Sun Z, Wang C, Shi C, Sun F, Xu X, Qian W, Nie S and Han X: Activated Wnt signaling induces myofibroblast differentiation of mesenchymal stem cells, contributing to pulmonary fibrosis. Int J Mol Med 33: 1097-1109, 2014.

24. Lagente V, Manoury B, Nénan S, Le Quément S, Martin-Chouly C and Boichot E: Role of matrix metalloproteinases in the development of airway inflammation and remodeling. J Med Biol Res 38: 1521-1530, 2005.

25. Kim JY, Choeng HC, Ahn C and Cho SH: Early and late changes of MMP-2 and MMP-9 in bleomycin-induced pulmonary fibrosis. Yonsei Med J 50: 68-77, 2009.

26. Wang Q, Zhu H, Zhou WG, Guo XC, Wu MJ, Xu ZY, Jiang JF, Shen C and Liu HQ: N-acetylcysteine-pretreated human embryonic mesenchymal stem cell administration protects against bleomycin-induced lung injury. Am J Med Sci 346: $113-122,2013$. 